\title{
Effects of curcumin on ion channels and transporters
}

\author{
Xuemei Zhang ${ }^{1}$, Qijing Chen ${ }^{1}$, Yunman Wang ${ }^{2}$, Wen Peng ${ }^{2 *}$ and Hui Cai ${ }^{3,4 *}$ \\ 1 Department of Pharmacology, School of Pharmacy, Fudan University, Shanghai, China \\ ${ }^{2}$ Department of Nephrology, Putuo Hospital, Shanghai University of Traditional Chinese Medicine, Shanghai, China \\ ${ }^{3}$ Renal Division, Department of Medicine, Department of Physiology, Emory University School of Medicine, Atlanta, GA, USA \\ ${ }^{4}$ Section of Nephrology, Atlanta Veterans Administration Medical Center, Decatur, GA, USA
}

Edited by:

He-Ping Ma, Emory University

School of Medicine, USA

\section{Reviewed by:}

Jeffrey Fedan, The National Institute

for Occupational Safety and Health,

USA

Zhen Wang, University of

Mississippi Medical Center, USA

${ }^{*}$ Correspondence:

Wen Peng, Department of

Nephrology, Putuo Hospital,

Shanghai University of Traditional

Chinese Medicine, No. 164, Lanxi

Road, Shanghai (200062), China

e-mail: wenpeng1968@aliyu.com;

Hui Cai, Renal Division, Department

of Medicine, Department of

Physiology, Emory University School

of Medicine, 201 Dowman Drive,

Atlanta, GA 30322, USA

e-mail: hcai3@emory.edu
Curcumin [1,7-bis(4-hydroxy-3-methoxyphenyl)-1,6-heptadiene-3,5-dione], a polyphenolic compound isolated from the rhizomes of Curcuma longa (turmeric), has been shown to exhibit a wide range of pharmacological activities including anti-inflammatory, anti-cancer, anti-oxidant, anti-atherosclerotic, anti-microbial, and wound healing effects. These activities of curcumin are based on its complex molecular structure and chemical features, as well as its ability to interact with multiple signaling molecules. The ability of curcumin to regulate ion channels and transporters was recognized a decade ago. The cystic fibrosis transmembrane conductance regulator (CFTR) is a well-studied ion channel target of curcumin. During the process of studying its anti-cancer properties, curcumin was found to inhibit ATP-binding cassette $(A B C)$ family members including $A B C A 1$, $A B C B 1, A B C C 1$, and $A B C G 2$. Recent studies have revealed that many channels and transporters are modulated by curcumin, such as voltage-gated potassium (Kv) channels, high-voltage-gated $\mathrm{Ca}^{2+}$ channels (HVGCC), volume-regulated anion channel (VRAC), $\mathrm{Ca}^{2+}$ release-activated $\mathrm{Ca}^{2+}$ channel (CRAC), aquaporin-4 (AQP-4), glucose transporters, etc., In this review, we aim to provide an overview of the interactions of curcumin with different types of ion channels and transporters and to help better understand and integrate the underlying molecular mechanisms of the multiple pharmacological activities of curcumin.

\section{Keywords: curcumin, ion channels, drug targets, transporters, membrane}

\section{INTRODUCTION}

Turmeric, the rhizome of Curcuma longa L. has been used since ancient times as a spice, coloring, flavoring, and traditional medicine. Curcumin [1,7-bis(4-hydroxy-3-methoxyphenyl)-1,6heptadiene-3,5-dione], an important active agent of turmeric, has been shown to exhibit a wide range of pharmacological activities including anti-inflammatory, anti-cancer, anti-oxidant, anti-atherosclerotic, anti-microbial, and wound healing effects (Maheshwari et al., 2006). These activities of curcumin are based on its chemical features, as well as its ability to interact with multiple signaling molecules. Many biological molecules have been identified as targets of curcumin, including transcription factors, growth factors, inflammatory cytokines, protein kinases and other enzymes (Zhou et al., 2011). The safety, tolerability, and non-toxicity of curcumin at high doses have been well established in many clinical trials. Different phase I clinical trials indicated that curcumin is well tolerated when taken in dose as high as $12 \mathrm{~g}$ per day. However, curcumin exhibits poor bioavailability at the same time (Anand et al., 2007). Thus, numerous approaches have been undertaken to improve its bioavailability, including the use of piperine, nanoparticles, liposomes, phospholipid complexes, and structural analogues (Gupta et al., 2013).

Studies have shown that curcumin influences a variety of ion channels and transporters across several signaling pathways, ranging from the well-studied CFTR to recently identified hERG potassium channel. The list is continuously expanding and it would not be surprising to find novel molecules in the future. Here, we summarized the known effects of curcumin on ion channels and transporters to help better understanding the underlying molecular mechanisms of multiple pharmacological activities of curcumin.

\section{EFFECTS OF CURCUMIN ON ION CHANNELS POTASSIUM CHANNELS}

$\mathrm{Kv}$ channels play important roles in regulating resting membrane potential. It has long been observed that cells possessing a high degree of polarization tend to be quiescent (Wonderlin and Strobl, 1996; Sundelacruz et al., 2009). As a potent blockage of $\mathrm{Kv}$ channels, curcumin reduces the Kv current in rabbit coronary arterial smooth muscle cells (Hong Da et al., 2013) and Jurkat T cells (Shin et al., 2011), inhibits Kv1.3 in effector memory T cells (TEM) (Lian et al., 2013), and blocks Kv11.1 potassium current in human monocytic leukemia (AML) cell lines THP-1 (Banderali et al., 2011) and HEK293 (Choi et al., 2013). Curcumin prevents $\mathrm{Kv}$ channel from activating, which consequently suppresses proliferation of AML cells and TEM cells, whereby exerts its anticancer or anti-inflammatory effects (Banderali et al., 2011; Lian et al., 2013). However, the mechanisms underlying the inhibitory effects of curcumin are not fully understood. Several studies suggest that curcumin inhibits Kv current via direct action on the Kv channels (Choi et al., 2013; Hong Da et al., 2013; Lian et al., 2013), possibly through its interaction with the pore blocker binding site (Choi et al., 2013). 
Curcumin is also an effective antinociceptive agent. Studies suggest that activation of $\mathrm{K}_{\mathrm{ATP}}$ channels, possibly by direct stimulation, contributes to the antinociceptive effect of curcumin (De Paz-Campos et al., 2012). Additional potential mechanisms of the antinociceptive effect of curcumin include activating $G_{i / o}$ proteins, stimulating the particular form of guanylyl cyclase or acting through the hydrogen sulfide-KATP channel pathway. Since the direct evidence is still lacking, further study is needed to fully reveal this mechanism. Curcumin has also been shown to inhibit intermediate-conductance $\mathrm{Ca}^{2+}$-activated $\mathrm{K}^{+}$channel (SK4) (Shin et al., 2012), but relevant physiological study is still elusive.

On the other hand, curcumin has been shown to open $\mathrm{K}^{+}$ channel. In goat ruminal artery, curcumin induces vasorelaxation by, at least in part, directly activating soluble guanylate cyclase (sGC) mediated cGMP pathway followed by the opening of $\mathrm{K}^{+}$ ion channel (Dash and Parija, 2013). Given the diverse regulatory effects of curcumin on multiple targets, it is not surprising that curcumin may participate in different pathways and lead to different physiological actions of $\mathrm{K}^{+}$channels.

\section{CALCIUM CHANNELS}

The increase of the intracellular $\mathrm{Ca}^{2+}$ concentration is widely viewed as the most important contributor to neurodegeneration and neuronal cell death (Duncan et al., 2010). Calcium channel blockade is one approach among the neuroprotective strategies (Singer, 2012). Curcumin has been demonstrated to reversibly inhibit HVGCC currents via a novel protein kinase C- $\theta$-dependent pathway, which could contribute to its neuroprotective effects in rat hippocampal neurons (Liu et al., 2013). In another study, it has been shown that curcumin inhibits glutamate release from rat prefrontocortical synaptosomes by suppressing presynaptic voltage-gated calcium channels Cav2.2 and Cav2.1 (Lin et al., 2011). This effect of curcumin might relate to the mechanisms underlying the antidepressant effect of curcumin. Curcumin has also been observed to inhibit $\mathrm{Ca}^{2+}$ release-activated $\mathrm{Ca}^{2+}$ (CRAC) channels (Shin et al., 2011, 2012).

Calcium influx is mainly mediated by store-operated $\mathrm{Ca}^{2+}$ entry (SOCE) through CRAC channels located in the plasma membrane, which is important for the activation and function of all cells in the immune system (Shaw et al., 2012). The inhibition of CRAC and another major ion channel Kv1.3 in lymphocytes might contribute to the anti-inflammatory effect of curcumin. The function of CRAC channels is primarily mediated by Orai proteins, which are located in the plasma membrane as the $\mathrm{Ca}^{2+}$ conducting pore unit (Shaw et al., 2012). Curcumin contains electrophilic $\alpha, \beta$-unsaturated carbonyl groups that potentially form Michael addition with cysteine residues. The electrophilic addition to the Orail 195Cys is responsible for the inhibitory effect of CRAC by curcumin (Choi et al., 2013).

\section{CHLORIDE CHANNELS}

CFTR acts as a $\mathrm{Cl}^{-}$channel on the apical membrane of epithelia. Mutations in the CFTR gene cause the reduction of CFTR expression or abnormalities in its function, thereby resulting in cystic fibrosis (CF), a genetic disease. The most common CFcausing mutation is $\triangle F 508-C F T R$, which leads to CFTR protein misfolding and retention in the endoplasmic reticulum (ER). Wild type and mutant CFTR channels can be activated by curcumin. Curcumin not only rescues $\triangle F 508$-CFTR localization by allowing $\triangle$ F508-CFTR to escape from ER and to anchor in the plasma membrane (Egan et al., 2004; Cartiera et al., 2010), but also stimulates its channel activity once it reaches the plasma membrane (Berger et al., 2005; Lipecka et al., 2006). This capacity of curcumin to release $\Delta$ F508-CFTR from the ER is likely due to the dissolution of the calnexin- $\Delta$ F508-CFTR complex and the stabilization of the tertiary structure of $\Delta$ F508-CFTR (Egan et al., 2004). Curcumin also potentiates another CF mutant channel, the glycine-to-aspartate missense mutation at position 551 (G551D). G551D-CFTR is the third most common CF-associated mutation, which is characterized by an extremely low open probability despite its normal trafficking to the plasma membrane (Miki et al., 2010). Curcumin increases the activity of the G551D-CFTR mutant channel (Yu et al., 2011). The cross-link of curcumin and these two CF mutant channels could be prevented by high concentrations of oxidant scavengers In Vitro, indicating a possible oxidation reaction of curcumin with the CFTR polypeptide (Bernard et al., 2009).

However, some studies fail to reproduce these results. Song et al. are unable to demonstrate the effectiveness of curcumin on the functional correction of the defective $\Delta$ F508-CFTR processing in transfected cells, native airway cells, and mutant mice (Song et al., 2004). Dragomir et al. have observed that curcumin causes a small increase in net cAMP-activated chloride efflux from $\Delta F 508$ CFTR expressing baby hamster kidney (BHK) cells, but fails to show the significant movements of $\triangle$ F508-CFTR to the plasma membrane in $\Delta$ F508-CFTR BHK cells (Dragomir et al., 2004). Gao et al. have shown that curcumin does not change CFTR expression level and forskolin-induced CFTR gating in MadinDarby canine kidney (MDCK) cell monolayer (Gao et al., 2011). These contradictions may be due to different genetic backgrounds of the animals studied, or different preparation of curcumin extract, etc. (Mall and Kunzelmann, 2005). Thus, although curcumin may be a desirable alternative for treating CF, its efficacy needs to be carefully evaluated (Mall and Kunzelmann, 2005).

VRAC plays an important role in regulating electrical and secretory activity in the $\beta$-cell. Curcumin activates VRAC, leading to $\mathrm{Cl}^{-}$efflux in $\beta$-cells. A study using single channel recording has indicated that this activation is the result of increased channel open probability (Gao et al., 2011). This study could partly explain the hypoglycemic action of curcumin.

\section{OTHER CHANNELS}

AQP-4, the predominant isoform of water channels in the brain, plays an important role in fluid generation, transfer, and absorption in brain. Curcumin attenuates the increase of AQP-4 expression induced by hypoxic-ischemic brain damage (HIBD) in the hippocampus (Yu et al., 2012). Since blood-brain barrier opening depends on the upregulation of AQP-4 function (Papadopoulos and Verkman, 2007), this study suggests that by down-regulating AQP-4, curcumin may protect astrocytic foot processes surrounding brain capillaries from damaging from HIBD edema. Curcumin could also block IL- $1 \beta$-induced AQP-4 expression in the cultured astrocytes and further reduce glial activation 
and cerebral edema following neurotrauma (Laird et al., 2010). However, in lupus erythematosus, curcumin increases brain AQP4 expression and water content (Foxley et al., 2013). Along with other evidence, it seems that curcumin aggravates some CNS disease manifestations in experimental lupus erythematosus.

Transient receptor potential (TRP) cation channel subfamily A member 1 (TRPA1) is a nociceptor specific ion channel expressed in a subset of TRPV1-expressing neurons. It has been an attractive target for various therapeutical interventions in the disease conditions, such as pain, asthma, and cough (Bandell et al., 2004). Curcumin causes activation and subsequent desensitization of native and recombinant TRPA1 ion channels of multiple mammalian species (Leamy et al., 2011). This effect may contribute to the analgesic effect of curcumin in patients with various chronic diseases (Di Pierro et al., 2013).

Curcumin is also a potent inhibitor of the inositol 1,4,5trisphosphate-sensitive $\mathrm{Ca}^{2+}$ channel (IP3 receptor). By inhibiting IP3 receptor, curcumin stimulates $\mathrm{Ca}^{2+}$ uptake, reduces $\mathrm{Ca}^{2+}$ leakage and inhibits IP3-induced $\mathrm{Ca}^{2+}$ release (IICR) from ER $\mathrm{Ca}^{2+}$ storage, blocks a multitude of subsequent $\mathrm{Ca}^{2+}$-dependent cellular events. This inhibition is likely non-competitive in nature (Dyer et al., 2002).

\section{EFFECTS OF CURCUMIN ON TRANSPORTERS ATP-BINDING CASSETTE (ABC) DRUG TRANSPORTER}

$A B C$ proteins are a large family of integral membrane proteins. They, collectively, serve a wide variety of cellular functions. $\mathrm{ABC}$ drug transporters actively transport a variety of amphipathic compounds. The overexpression of $\mathrm{ABC}$ drug transporters causes multidrug resistance (MDR) in cancer cells. Among $\mathrm{ABC}$ transporter family, three of them, ABCB1 (P-glycoprotein/Pgp), ABCC1 (multidrug resistance protein 1/MRP1) and ABCG2 (breast cancer resistance protein /MXR/BCRP) appear to play an important role in the development of MDR in cancer cells (Wu et al., 2008; Orina et al., 2009). Curcumin has been studied as a potential anticancer drug for many years, not only because of its antiproliferative or apoptosis-inducing effect on several cancer cells, but also due to its ability to reverse MDR phenotypes in several cancer cells overexpressing $\mathrm{ABC}$ transporters, such as, ABCB1, ABCC1, and ABCG2 (Sharma et al., 2009). Curcuminoids (including curcumin, demethoxycurcumin and bisdemethoxycurcumin) sensitizes the ABCG2-expressing cells to conventional chemotherapeutic agent mitoxantrone, topotecan, SN-38, and doxorubicin. The reversal of resistance is due to their influence on the function rather than the protein levels of ABCG2 (Chearwae et al., 2006). Curcumin also inhibits ABCG2-mediated efflux of sulfasalazine and increases the area under the curve (AUC) of plasma sulphasalazine both in vivo (Shukla et al., 2009) and in vitro (Kusuhara et al., 2012). In the case of ABCB1 (Pgp), its overexpression on the surface of tumor cells is often linked to MDR. In the multidrug-resistant human cervical carcinoma cell line KB-V1, curcumin is able to significantly lower the Pgp expression and reduce the function of Pgp. Curcumin is not a substrate for Pgp, but it interacts directly with drug binding site of the transporter (Anuchapreeda et al., 2002; Limtrakul et al., 2007). Treatment of KB-V1 cells with curcumin increases their sensitivity to vinblastine (Anuchapreeda et al.,
2002; Limtrakul et al., 2007). In MCF-7/ADR cells overexpressing Pgp, curcumin significantly enhances the cellular accumulation of rhodamine-123 in a concentration-dependent manner, indicating that curcumin significantly inhibits Pgp activity (Cho et al., 2012). This evidence suggests that curcumin could be an effective MDR modulator, and may be used in combination with conventional chemotherapeutic drugs to reverse MDR in cancer cells.

Needless to say, the trafficking of curcumin depends on transporters as well. Curcumin-resistance has also been observed in some cancer cells, and efflux of curcumin by $\mathrm{ABC}$ transporters is considered as one of the factors causing resistance. In hypoxiainduced curcumin-resistance in HepG2 cells, the expression of $\mathrm{ABC}$ drug transporter genes, including $\mathrm{ABCC} 1, \mathrm{ABCC} 2$, and $A B C C 3$, are increased by more than two-fold. Both inhibitors of $A B C C 1 / A B C C 2$ are able to reverse this curcumin resistance (Sakulterdkiat et al., 2012). In resistant M14 melanoma cells, the ABCA1 is over-expressed as compared to that in the curcuminsensitive MDA-MB-231 breast cancer cells. Gene silencing of ABCA1 sensitizes M14 cells to the apoptotic effect of curcumin (Bachmeier et al., 2009). Therefore, the expression level of the involved $\mathrm{ABC}$ drug transporters should be monitored as potential response predictors in curcumin treatment for certain types of cancer.

ABC molecules, especially ABCA and ABCG subfamily members, are critical in the regulation of lipid-trafficking as well (Schmitz et al., 2001), through which curcumin affects lipid metabolism, contributing its beneficial effects on inflammation, cardiovascular diseases and obesity. In macrophages, treatment with curcumin markedly ameliorates cholesterol accumulation by increasing cholesterol efflux, due to up-regulation of ABCA1. Curcumin administration modulates the expression of ABCA1 and ABCG1 in apoE ${ }^{-1-}$ mice (Zhao et al., 2012). Curcumin also increases the cholesterol efflux from adipocytes. The increased expressions of PPAR $\gamma, \mathrm{LXR} \alpha$ and ABCA1 induced by curcumin are parallel and correlated, suggesting that curcumin can affect the cholesterol efflux from adipocytes by regulating the PPAR $\gamma$ LXR-ABCA1 pathway (Dong et al., 2011).

\section{GLUCOSE TRANSPORTER (GLUT)}

One of the merits for curcumin used as an anti-diabetic medication is its ability to lower blood glucose likely by interacting with GLUT. Evidence suggests curcumin influences subtypes of GLUT. Hyperglycemia stimulates hepatic stellate cell (HSC) activation in vitro by increasing intracellular glucose. Curcumin eliminates this stimulatory effect via blocking the membrane translocation of GLUT2 and suppressing GLUT2 expression. The former effect is mediated by interrupting the p38 MAPK signaling pathway and the latter by activating $\operatorname{PPAR} \gamma$ and attenuating oxidative stress (Lin and Chen, 2011). In the leptin-induced HSC activation, curcumin suppresses the membrane translocation of GLUT4 by interrupting the insulin receptor substrates (IRS)/PI3K/AKT signaling pathway (Tang and Chen, 2010). On the other hand, Cheng et al. have shown that curcumin causes a concentration-dependent increase of glucose uptake by skeletal muscle cells isolated from Wistar rats, and this action is mediated by increasing membrane protein level of GLUT4 (Cheng et al., 
2009). The increased GLUT4 is reversed by blocking muscarinic M-1 cholinoceptor $\left(\mathrm{M}_{1}-\mathrm{mAChR}\right)$ or PLC/PI3K pathway. These phenomena suggest that the effects of curcumin on GLUT are complicated and may be tissue specific and/or signaling pathwaydependent.

\section{OTHER TRANSPORTERS}

Glutamate facilitates the pathogenesis of post-ischemic neuronal injury. Glutamate transporter-1 (GLT-1) is essential for maintaining a low extracellular glutamate concentration and for preventing glutamate neurotoxcity. Curcumin may reduce cerebral vasospasm (CVS) and neurologic injury via an antioxidant effect and attenuate glutamate-induced neurotoxicity. In a subarachnoid hemorrhage (SAH)-induced rat CVS model, glutamate levels are lower in the curcumin treated group vs. the saline and vehicle treated groups. Correspondingly, GLT-1 is preserved after SAH in curcumin-treated rats (Kuo et al., 2011). These results suggest that curcumin may modulate GLT-1.

Curcumin increases the expression of two lipid transport genes, the fatty acids transporter CD36/FAT and the fatty acids binding protein 4 (FABP4/aP2) in THP-1 and RAW264.7 monocytes and macrophages, leading to increased lipid levels in THP-1 and RAW264.7 (Zingg et al., 2012), though the significance of the findings on the effect of curcumin against oxidant and lipidinduced damage needs to be further studied.

Intestinal Niemann-Pick C1-like 1 (NPC1L1) cholesterol transporter plays an essential role in the maintenance of cholesterol homeostasis. Curcumin exhibits effects of lowering plasma cholesterol and preventing diet-induced hypercholesterolemia. Treating Caco-2 cell monolayers with curcumin significantly inhibits cholesterol esterification and uptake. Coincidentally, the NPC1L1 mRNA level and protein expression are significantly decreased (Feng et al., 2010; Kumar et al., 2011). This evidence suggests that hypocholesterolemic effect of curcumin may be linked to the suppression of NPC1L1 expression in the intestinal cells.

\section{MECHANISMS UNDERLYING REGULATORY EFFECTS OF CURCUMIN}

Although it has been under intensive investigations and scientific debates, the detailed mechanisms underlying the diverse effects of curcumin remain elusive. One argument is that curcumin is a modulator of membrane structure; it may affect the membrane proteins in a non-specific way. Ingolfsson et al. explored whether curcumin modifies general lipid bilayer properties using channels formed by gramicidin A (gA). They found that curcumin decreases the stiffness of the lipid-bilayer and increases the lifetimes and appearance rates of gA channel, suggesting that the energetic cost of the gA-induced bilayer deformation is reduced (Ingolfsson et al., 2007). Another study showed that curcumin affects membrane structure in a manner analogous to lipophillic drugs, which are inserted deeply into the membrane in a transbilayer orientation and anchored by hydrogen bonding to the phosphate group of lipids (Barry et al., 2009). Other studies, however, demonstrated that curcumin possesses a specific property or mechanism underlying its modulation of the transporters or channels. In a case of CFTR regulation, curcumin is able to cross-link CFTR polypeptides and phosphorylate the $\mathrm{R}$ domain of CFTR channel (Bernard et al., 2009). For the hERG potassium channel, curcumin exerts the pore-blocking effect (Choi et al., 2013). The effect of curcumin on TRPV1 channel is dependent on disease conditions. Curcumin exerts no effects on the TRPV1 channel in normal tissue, whereas activates TRPV1 channel in colitis (Martelli et al., 2007). These studies suggest that curcumin exhibits its unique effects on ion channels and transporters through different mechanisms far beyond a non-specific effect although some of curcumin's effectiveness may be membranemediated. The exact mechanisms on each particular channel and transporter need to be further elucidated.

\section{CONCLUSION}

These studies have provided ample evidence that curcumin affects a variety of ion channels and transporters, and hence modulates various critical physiological functions. In many circumstances, regulatory effects of curcumin may be presented with a multifaceted nature given the multiple targets and different pathways in which curcumin is involved. Despite there being several clinical trials involving curcumin, no clear clinical indication has been yet defined. More studies are needed to fully evaluate the efficacy of curcumin in its utility as a therapeutic agent for the different diseases. Nevertheless, given its potential multiple targets, pharmacological safety and enhanced bioavailability, curcumin is a promising natural product that is likely to be brought to the forefront of therapeutic agents for treatment of human diseases in the future.

\section{ACKNOWLEDGMENTS}

This work is supported by the National Science Foundation of China No 81370979 (Xuemei Zhang), Shanghai Science and Technology Innovation Grant 12140903000 (Xuemei Zhang), Leading Academic Discipline Project of SATCM (Wen Peng), Talent project of integrative medicine of Shanghai municipal health bureau(Wen Peng) and Department of Veteran Affairs MERIT Award 5I01BX000994 (Hui Cai)

\section{REFERENCES}

Anand, P., Kunnumakkara, A. B., Newman, R. A., and Aggarwal, B. B. (2007). Bioavailability of curcumin: problems and promises. Mol. Pharm. 4, 807-818. doi: $10.1021 / \mathrm{mp} 700113 \mathrm{r}$

Anuchapreeda, S., Leechanachai, P., Smith, M. M., Ambudkar, S. V., and Limtrakul, P. N. (2002). Modulation of P-glycoprotein expression and function by curcumin in multidrug-resistant human KB cells. Biochem. Pharmacol. 64, 573-582. doi: 10.1016/S0006-2952(02)01224-8

Bachmeier, B. E., Iancu, C. M., Killian, P. H., Kronski, E., Mirisola, V., Angelini, G., et al. (2009). Overexpression of the ATP binding cassette gene ABCA1 determines resistance to Curcumin in M14 melanoma cells. Mol. Cancer 8, 129. doi: 10.1186/1476-4598-8-129

Bandell, M., Story, G. M., Hwang, S. W., Viswanath, V., Eid, S. R., Petrus, M. J., et al. (2004). Noxious cold ion channel TRPA1 is activated by pungent compounds and bradykinin. Neuron 41, 849-857. doi: 10.1016/S0896-6273(04)00150-3

Banderali, U., Belke, D., Singh, A., Jayanthan, A., Giles, W. R., and Narendran, A. (2011). Curcumin blocks Kv11.1 (erg) potassium current and slows proliferation in the infant acute monocytic leukemia cell line THP-1. Cell. Physiol. Biochem. 28, 1169-1180. doi: 10.1159/000335850

Barry, J., Fritz, M., Brender, J. R., Smith, P. E., Lee, D. K., and Ramamoorthy, A. (2009). Determining the effects of lipophilic drugs on membrane structure by solid-state NMR spectroscopy: the case of the antioxidant curcumin. J. Am. Chem. Soc. 131, 4490-4498. doi: 10.1021/ja809217u 
Berger, A. L., Randak, C. O., Ostedgaard, L. S., Karp, P. H., Vermeer, D. W., and Welsh, M. J. (2005). Curcumin stimulates cystic fibrosis transmembrane conductance regulator Cl- channel activity. J. Biol. Chem. 280, 5221-5226. doi: 10.1074/jbc.M412972200

Bernard, K., Wang, W., Narlawar, R., Schmidt, B., and Kirk, K. L. (2009). Curcumin cross-links cystic fibrosis transmembrane conductance regulator (CFTR) polypeptides and potentiates CFTR channel activity by distinct mechanisms. J. Biol. Chem. 284, 30754-30765. doi: 10.1074/jbc.M109.056010

Cartiera, M. S., Ferreira, E. C., Caputo, C., Egan, M. E., Caplan, M. J., and Saltzman, W. M. (2010). Partial correction of cystic fibrosis defects with PLGA nanoparticles encapsulating curcumin. Mol. Pharm. 7, 86-93. doi: 10.1021/mp900138a

Chearwae, W., Shukla, S., Limtrakul, P., and Ambudkar, S. V. (2006). Modulation of the function of the multidrug resistance-linked ATP-binding cassette transporter ABCG2 by the cancer chemopreventive agent curcumin. Mol. Cancer Ther. 5, 1995-2006. doi: 10.1158/1535-7163.MCT-06-0087

Cheng, T. C., Lin, C. S., Hsu, C. C., Chen, L. J., Cheng, K. C., and Cheng, J. T. (2009). Activation of muscarinic M-1 cholinoceptors by curcumin to increase glucose uptake into skeletal muscle isolated from Wistar rats. Neurosci. Lett. 465 238-241. doi: 10.1016/j.neulet.2009.09.012

Cho, Y. A., Lee, W., and Choi, J. S. (2012). Effects of curcumin on the pharmacokinetics of tamoxifen and its active metabolite, 4-hydroxytamoxifen, in rats: possible role of CYP3A4 and P-glycoprotein inhibition by curcumin. Pharmazie 67, 124-130. doi: 10.1691/ph.2012.1099

Choi, S. W., Kim, K. S., Shin, D. H., Yoo, H. Y., Choe, H., Ko, T. H., et al. (2013). Class 3 inhibition of hERG $\mathrm{K}(+)$ channel by caffeic acid phenethyl ester (CAPE) and curcumin. Pflugers Arch. 465, 1121-1134. doi: 10.1007/s00424-013-1239-7

Dash, J., and Parija, S. (2013). Spasmolytic effect of curcumin on goat ruminal artery is endothelium independent and by activation of sGC. Res. Vet. Sci. 95, 588-593. doi: 10.1016/j.rvsc.2013.04.029

De Paz-Campos, M. A., Chavez-Pina, A. E., Ortiz, M. I., and Castaneda-Hernandez, G. (2012). Evidence for the Participation of ATP-sensitive potassium channels in the antinociceptive effect of Curcumin. Kor. J. Pain 25, 221-227. doi: 10.3344/kjp.2012.25.4.221

Di Pierro, F., Rapacioli, G., Di Maio, E. A., Appendino, G., Franceschi, F., and Togni, S. (2013). Comparative evaluation of the pain-relieving properties of a lecithinized formulation of curcumin (Meriva $\left({ }^{\circledR}\right)$ ), nimesulide, and acetaminophen. J. Pain Res. 6, 201-205. doi: 10.2147/JPR.S42184

Dong, S. Z., Zhao, S. P., Wu, Z. H., Yang, J., Xie, X. Z., Yu, B. L., et al. (2011). Curcumin promotes cholesterol efflux from adipocytes related to PPARgamma-LXRalpha-ABCA1 passway. Mol. Cell. Biochem. 358, 281-285. doi: 10.1007/s11010-011-0978-Z

Dragomir, A., Björstad, J., Hjelte, L., and Roomans, G. M. (2004). Curcumin does not stimulate cAMP-mediated chloride transport in cystic fibrosis airway epithelial cells. Biochem. Biophys. Res. Commun. 322, 447-451. doi: 10.1016/j.bbrc.2004.07.146

Duncan, R. S., Goad, D. L., Grillo, M. A., Kaja, S., Payne, A. J., and Koulen, P. (2010). Control of intracellular calcium signaling as a neuroprotective strategy. Molecules 15, 1168-1195. doi: 10.3390/molecules 15031168

Dyer, J. L., Khan, S. Z., Bilmen, J. G., Hawtin, S. R., Wheatley, M., Javed, M. U., et al. (2002). Curcumin: a new cell-permeant inhibitor of the inositol 1,4,5-trisphosphate receptor. Cell Calcium 31, 45-52. doi: 10.1054/ceca.20 01.0259

Egan, M. E., Pearson, M., Weiner, S. A., Rajendran, V., Rubin, D., Glockner-Pagel, J. et al. (2004). Curcumin, a major constituent of turmeric, corrects cystic fibrosis defects. Science 304, 600-602. doi: 10.1126/science.1093941

Feng, D., Ohlsson, L., and Duan, R. D. (2010). Curcumin inhibits cholesterol uptake in Caco-2 cells by down-regulation of NPC1L1 expression. Lipids Health Dis. 9, 40. doi: 10.1186/1476-511X-9-40

Foxley, S., Zamora, M., Hack, B., Alexander, R. R., Roman, B., Quigg, R. J., et al. (2013). Curcumin aggravates CNS pathology in experimental systemic lupus erythematosus. Brain Res. 1504, 85-96. doi: 10.1016/j.brainres.2013.0 1.040

Gao, J., Zhou, H., Lei, T., Zhou, L., Li, W., Li, X., et al. (2011). Curcumin inhibits renal cyst formation and enlargement in vitro by regulating intracellular signaling pathways. Eur. J. Pharmacol. 654, 92-99. doi: 10.1016/j.ejphar.2010.1 2.008

Gupta, S. C., Patchva, S., and Aggarwal, B. B. (2013). Therapeutic roles of curcumin: lessons learned from clinical trials. AAPS J. 15, 195-218. doi: 10.1208/s12248-01 2-9432-8
Hong Da, H., Son, Y. K., Choi, I. W., and Park, W. S. (2013). The inhibitory effect of curcumin on voltage-dependent $\mathrm{K}(+)$ channels in rabbit coronary arterial smooth muscle cells. Biochem. Biophys. Res. Commun. 430, 307-312. doi: 10.1016/j.bbrc.2012.10.132

Ingolfsson, H. I., Koeppe Ii, R. E., and Andersen, O. S. (2007). Curcumin is a modulator of bilayer material properties. Biochemistry 46, 10384-10391. doi: 10.1021/bi701013n

Kumar, P., Malhotra, P., Ma, K., Singla, A., Hedroug, O., Saksena, S., et al. (2011). SREBP2 mediates the modulation of intestinal NPC1L1 expression by curcumin. Am. J. Physiol. Gastrointest. Liver Physiol. 301, G148-G155. doi: 10.1152/ajpgi.00119.2011

Kuo, C. P., Lu, C. H., Wen, L. L., Cherng, C. H., Wong, C. S., Borel, C. O., et al. (2011). Neuroprotective effect of curcumin in an experimental rat model of subarachnoid hemorrhage. Anesthesiology 115, 1229-1238. doi: 10.1097/ALN.0b013e31823306f0

Kusuhara, H., Furuie, H., Inano, A., Sunagawa, A., Yamada, S., Wu, C., et al. (2012). Pharmacokinetic interaction study of sulphasalazine in healthy subjects and the impact of curcumin as an in vivo inhibitor of BCRP. Br. J. Pharmacol. 166, 1793-1803. doi: 10.1111/j.1476-5381.2012.01887.x

Laird, M. D., Sukumari-Ramesh, S., Swift, A. E., Meiler, S. E., Vender, J. R., and Dhandapani, K. M. (2010). Curcumin attenuates cerebral edema following traumatic brain injury in mice: a possible role for aquaporin-4? J. Neurochem. 113, 637-648. doi: 10.1111/j.1471-4159.2010.06630.x

Leamy, A. W., Shukla, P., Mcalexander, M. A., Carr, M. J., and Ghatta, S. (2011). Curcumin ((E,E)-1,7-bis(4-hydroxy-3-methoxyphenyl)-1,6-heptadiene-3,5dione) activates and desensitizes the nociceptor ion channel TRPA1. Neurosci. Lett. 503, 157-162. doi: 10.1016/j.neulet.2011.07.054

Lian, Y. T., Yang, X. F., Wang, Z. H., Yang, Y., Shu, Y. W., Cheng, L. X., et al. (2013). Curcumin serves as a human Kv1.3 blocker to inhibit effector memory T Lymphocyte activities. Phytother. Res. 27, 1321-1327. doi: 10.1002/ptr.4863

Limtrakul, P., Chearwae, W., Shukla, S., Phisalphong, C., and Ambudkar, S. V. (2007). Modulation of function of three ABC drug transporters, P-glycoprotein $(\mathrm{ABCB} 1)$, mitoxantrone resistance protein (ABCG2) and multidrug resistance protein 1 (ABCC1) by tetrahydrocurcumin, a major metabolite of curcumin. Mol. Cell. Biochem. 296, 85-95. doi: 10.1007/s11010-006-9302-8

Lin, J., and Chen, A. (2011). Curcumin diminishes the impacts of hyperglycemia on the activation of hepatic stellate cells by suppressing membrane translocation and gene expression of glucose transporter-2. Mol. Cell. Endocrinol. 333, 160-171. doi: 10.1016/j.mce.2010.12.028

Lin, T. Y., Lu, C. W., Wang, C.-C., Wang, Y.-C., and Wang, S.-J. (2011). Curcumin inhibits glutamate release in nerve terminals from rat prefrontal cortex: possible relevance to its antidepressant mechanism. Prog. Neuropsychopharmacol. Biol. Psychiatry 35, 1785-1793. doi: 10.1016/j.pnpbp.2011.06.012

Lipecka, J., Norez, C., Bensalem, N., Baudouin-Legros, M., Planelles, G., Becq, F., et al. (2006). Rescue of DeltaF508-CFTR (cystic fibrosis transmembrane conductance regulator) by curcumin: involvement of the keratin 18 network. J. Pharmacol. Exp. Ther. 317, 500-505. doi: 10.1124/jpet.105.097667

Liu, K., Gui, B., Sun, Y., Shi, N., Gu, Z., Zhang, T., et al. (2013). Inhibition of L-type $\mathrm{Ca}(2+)$ channels by curcumin requires a novel protein kinasetheta isoform in rat hippocampal neurons. Cell Calcium 53, 195-203. doi: 10.1016/j.ceca.2012.11.014

Maheshwari, R. K., Singh, A. K., Gaddipati, J., and Srimal, R. C. (2006). Multiple biological activities of curcumin: a short review. Life Sci. 78, 2081-2087. doi: 10.1016/j.lfs.2005.12.007

Mall, M., and Kunzelmann, K. (2005). Correction of the CF defect by curcumin: hypes and disappointments. Bioessays 27, 9-13. doi: 10.1002/bies.20168

Martelli, L., Ragazzi, E., Di Mario, F., Martelli, M., Castagliuolo, I., Dal Maschio, M., et al. (2007). A potential role for the vanilloid receptor TRPV1 in the therapeutic effect of curcumin in dinitrobenzene sulphonic acid-induced colitis in mice. Neurogastroenterol. Motil. 19, 668-674. doi: 10.1111/j.1365-2982.2007.0 0928.x

Miki, H., Zhou, Z., Li, M., Hwang, T.-C., and Bompadre, S. G. (2010). Potentiation of disease-associated cystic fibrosis transmembrane conductance regulator mutants by hydrolyzable ATP analogs. J. Biol. Chem. 285, 19967-19975. doi: 10.1074/jbc.M109.092684

Orina, J. N., Calcagno, A. M., Wu, C.-P., Varma, S., Shih, J., Lin, M., et al. (2009). Evaluation of current methods used to analyze the expression profiles of ATPbinding cassette transporters yields an improved drug-discovery database. $\mathrm{Mol}$. Cancer Ther. 8, 2057-2066. doi: 10.1158/1535-7163.MCT-09-0256 
Papadopoulos, M. C., and Verkman, A. S. (2007). Aquaporin-4 and brain edema. Pediatr. Nephrol. 22, 778-784. doi: 10.1007/s00467-006-0411-0

Sakulterdkiat, T., Srisomsap, C., Udomsangpetch, R., Svasti, J., and Lirdprapamongkol, K. (2012). Curcumin resistance induced by hypoxia in HepG2 cells is mediated by multidrug-resistance-associated proteins. Anticancer Res. 32, 5337-5342.

Schmitz, G., Langmann, T., and Heimerl, S. (2001). Role of ABCG1 and other ABCG family members in lipid metabolism. J. Lipid Res. 42, 1513-1520.

Sharma, M., Manoharlal, R., Shukla, S., Puri, N., Prasad, T., Ambudkar, S. V., et al. (2009). Curcumin modulates efflux mediated by yeast ABC multidrug transporters and is synergistic with antifungals. Antimicrob. Agents Chemother. 53, 3256-3265. doi: 10.1128/AAC.01497-08

Shaw, P. J., Qu, B., Hoth, M., and Feske, S. (2012). Molecular regulation of CRAC channels and their role in lymphocyte function. Cell. Mol. Life Sci. 1-20. doi: 10.1007/s00018-012-1175-2

Shin, D. H., Nam, J. H., Lee, E. S., Zhang, Y., and Kim, S. J. (2012). Inhibition of $\mathrm{Ca}(2+)$ release-activated $\mathrm{Ca}(2+)$ channel (CRAC) by curcumin and caffeic acid phenethyl ester (CAPE) via electrophilic addition to a cysteine residue of Orai1. Biochem. Biophys. Res. Commun. 428, 56-61. doi: 10.1016/j.bbrc.2012.10.005

Shin, D. H., Seo, E. Y., Pang, B., Nam, J. H., Kim, H. S., Kim, W. K., et al. (2011). Inhibition of $\mathrm{Ca}(2+)$-release-activated $\mathrm{Ca}(2+)$ channel (CRAC) and $\mathrm{K}(+)$ channels by curcumin in Jurkat-T cells. J. Pharmacol. Sci. 115, 144-154. doi: $10.1254 /$ jphs.10209FP

Shukla, S., Zaher, H., Hartz, A., Bauer, B., Ware, J. A., and Ambudkar, S. V. (2009). Curcumin inhibits the activity of ABCG2/BCRP1, a multidrug resistance-linked ABC drug transporter in mice. Pharm. Res. 26, 480-487. doi: 10.1007/s11095008-9735-8

Singer, C. (2012). Managing the patient with newly diagnosed Parkinson disease. Cleve. Clin. J. Med. 79, S3-S7. doi: 10.3949/ccim.79.s2a.01

Song, Y., Sonawane, N. D., Salinas, D., Qian, L., Pedemonte, N., Galietta, L. J., et al. (2004). Evidence against the rescue of defective DeltaF508-CFTR cellular processing by curcumin in cell culture and mouse models. J. Biol. Chem. 279, 40629-40633. doi: 10.1074/jbc.M407308200

Sundelacruz, S., Levin, M., and Kaplan, D. L. (2009). Role of membrane potential in the regulation of cell proliferation and differentiation. Stem Cell Rev. Rep. 5, 231-246. doi: 10.1007/s12015-009-9080-2

Tang, Y., and Chen, A. (2010). Curcumin prevents leptin raising glucose levels in hepatic stellate cells by blocking translocation of glucose transporter4 and increasing glucokinase. Br. J. Pharmacol. 161, 1137-1149. doi: $10.1111 / \mathrm{j} .1476-5381.2010 .00956 . \mathrm{x}$
Wonderlin, W., and Strobl, J. (1996). Potassium channels, proliferation and G1 progression. J. Membr. Biol. 154, 91-107. doi: 10.1007/s002329900135

Wu, C.-P., Calcagno, A. M., and Ambudkar, S. V. (2008). Reversal of ABC drug transporter-mediated multidrug resistance in cancer cells: evaluation of current strategies. Curr. Mol. Pharmacol. 1, 93. doi: 10.2174/187446721080 1020093

Yu, L., Yi, J., Ye, G., Zheng, Y., Song, Z., Yang, Y., et al. (2012). Effects of curcumin on levels of nitric oxide synthase and AQP-4 in a rat model of hypoxia-ischemic brain damage. Brain Res. 1475, 88-95. doi: 10.1016/j.brainres.2012.07.055

Yu, Y. C., Miki, H., Nakamura, Y., Hanyuda, A., Matsuzaki, Y., Abe, Y., et al. (2011). Curcumin and genistein additively potentiate G551D-CFTR. J. Cyst. Fibros. 10, 243-252. doi: 10.1016/j.jcf.2011.03.001

Zhao, J. F., Ching, L. C., Huang, Y. C., Chen, C. Y., Chiang, A. N., Kou, Y. R., et al. (2012). Molecular mechanism of curcumin on the suppression of cholesterol accumulation in macrophage foam cells and atherosclerosis. Mol. Nutr. Food Res. 56, 691-701. doi: 10.1002/mnfr.201100735

Zhou, H., Beevers, C. S., and Huang, S. (2011). The targets of curcumin. Curr. Drug Targets 12, 332-347. doi: 10.2174/138945011794815356

Zingg, J. M., Hasan, S. T., Cowan, D., Ricciarelli, R., Azzi, A., and Meydani, M. (2012). Regulatory effects of curcumin on lipid accumulation in monocytes/macrophages. J. Cell. Biochem. 113, 833-840. doi: 10.1002/jcb.2 3411

Conflict of Interest Statement: The authors declare that the research was conducted in the absence of any commercial or financial relationships that could be construed as a potential conflict of interest.

Received: 16 January 2014; accepted: 21 February 2014; published online: 11 March 2014.

Citation: Zhang X, Chen Q, Wang Y, Peng W and Cai H (2014) Effects of curcumin on ion channels and transporters. Front. Physiol. 5:94. doi: 10.3389/fphys.2014.00094 This article was submitted to Renal and Epithelial Physiology, a section of the journal Frontiers in Physiology.

Copyright (c) 2014 Zhang, Chen, Wang, Peng and Cai. This is an open-access article distributed under the terms of the Creative Commons Attribution License (CC BY). The use, distribution or reproduction in other forums is permitted, provided the original author(s) or licensor are credited and that the original publication in this journal is cited, in accordance with accepted academic practice. No use, distribution or reproduction is permitted which does not comply with these terms. 